\title{
Antibiogram of Urinary Pathogens in Patients with Diabetes Mellitus - Experience from a Tertiary Care Hospital
}

\author{
B.K. Rashmi* and D.T. Venkatesha \\ Department of Microbiology, Hassan Institute of Medical Sciences, \\ Hassan 573201, Karnataka, India \\ *Corresponding author
}

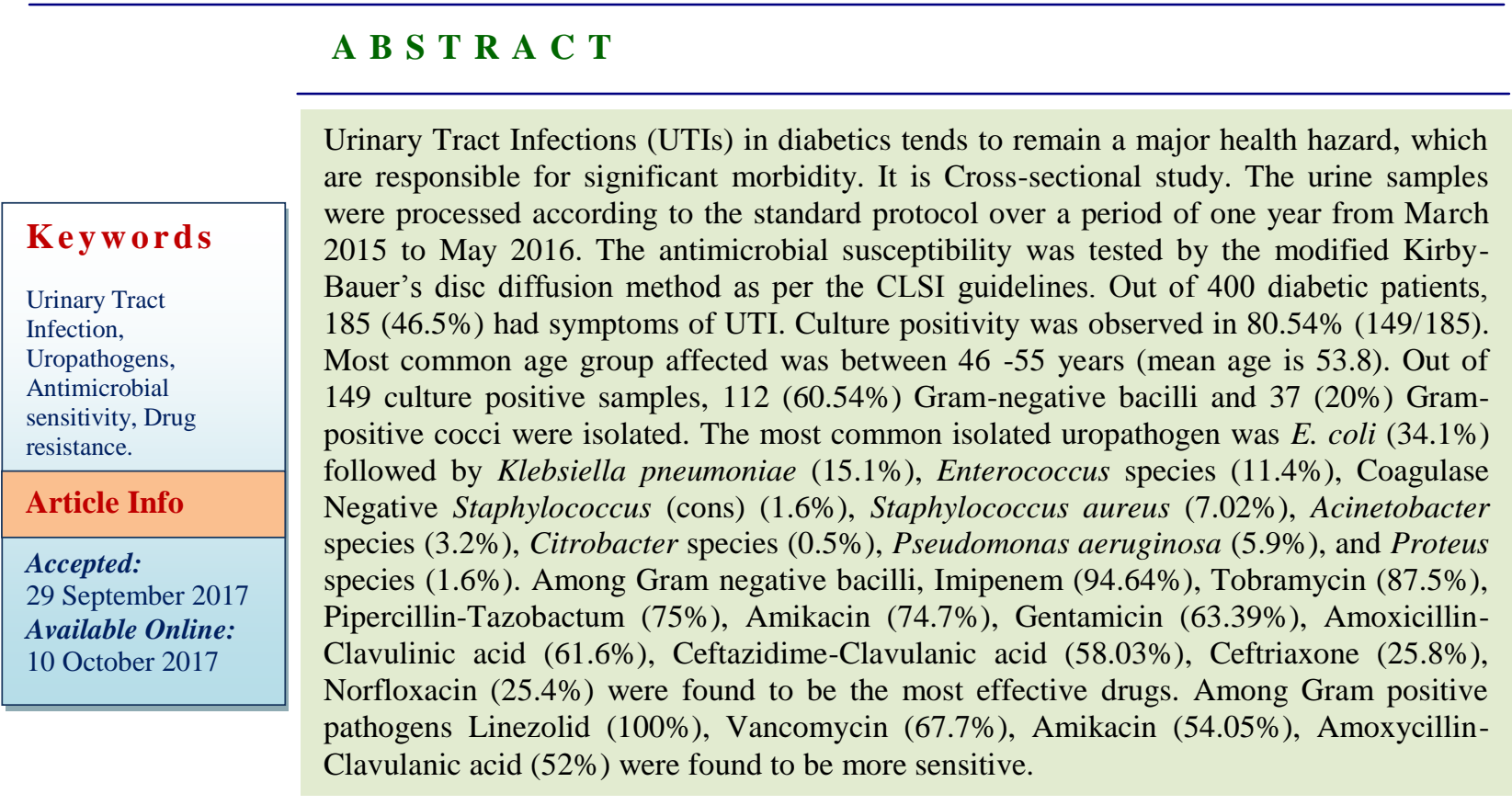

\section{Introduction}

Urinary tract infections (UTI) are the most common infections in clinical practice. ${ }^{1}$ it has been estimated that globally symptomatic UTIs result in as many as seven million visits to outpatient clinics. ${ }^{2}$ the urinary tract is the principal site of infection in diabetes. Changes in host defence mechanisms, the presence of diabetic cystopathy and of microvascular disease in the kidneys may play a role in the higher incidence of UTI in diabetic patients. ${ }^{3}$ the most common pathogenic organisms of UTI are Escherichia coli, Staphylococcus saprophyticus and less common organisms are Proteus species, Klebsiella pneumoniae, Pseudomonas aeruginosa, Enterococci and Candida albicans. ${ }^{4}$ Treatment of UTI cases is often started empirically and therapy is based on information determined from the antimicrobial resistance pattern of the urinary pathogens. ${ }^{5}$ In spite of the availability and use of the antimicrobial drugs, UTIs caused by bacteria have been showing increasing in antibiotic resistance in urinary tract pathogens. ${ }^{6}$ 
The prevalence of antimicrobial resistance in urinary pathogens is increasing worldwide. Accurate bacteriologic records of culture results may provide guidance on empirical therapy before sensitivity patterns are available. ${ }^{7}$

\section{Materials and Methods}

The present study has been carried out at the department of Microbiology, Sri Chamarajendra Hospital, HIMS, HASSAN, Karnataka state, India from March 2015 to May 2016. It is a cross-sectional study. Out of 400 diabetic patients, 185 (46.5\%) had symptoms of UTI. They were included in the study.

Method of sample collection and processing: A freshly voided midstream urine samples $(10-20 \mathrm{ml})$ were collected from UTI suspected patients.

Blood agar, Mac Conkey agar and Nutrient agar were prepared as per the standard guidelines (HiMEDIA).

A loop full $(0.001 \mathrm{~mL})$ of each urine sample obtained from patients was streaked on MacConkey agar and Blood agar for the growth of bacteria and the culture plates were incubated in an inverted position at $37^{\circ} \mathrm{C}$ under aerobic condition for 24 to $48 \mathrm{hrs}$. Reinoculation of mixed cultures was further made on blood agar and nutrient agar medium for each discrete colony presented in specimen to obtain well-isolated pure colonies and the pure colonies were preserved for Gram's staining. ${ }^{8}$

Gram staining was done for all isolates as per the standard procedures and the smears were examined microscopically, for their morphology, and staining reactions. All the isolates were identified initially by colony characters, hemolysis on blood agar, lactose fermentation, morphology in Gram staining, Catalase Test, Oxidase test and motility (hanging drop) test. The preliminary identification of potential pathogens, later confirmed up to species level by standard biochemical tests. The data were analyzed using SPSS software 20 (Statistical tests for social package for windows)

\section{Results and Discussion}

Total of four hundred patients of diabetes mellitus were screened for urinary tract infection. Among them 185 patients were found to have urinary tract infection. The prevalence corresponds to $46.5 \%$.

A total of 185 samples were collected in the study period of one to one and half year, of which $110(59.5 \%)$ were from female and 75 (40.5\%) were from male (Table 1). Culture positivity was $80.54 \% \quad(149 / 185)$ for significant bacteriuria irrespective of all age groups and sex. In this study, out of 149 culture positive samples, 112 (60.54\%) Gramnegative bacilli and 37 (20\%) Gram-positive cocci were isolated (Figure 1).

The most common isolated uropathogen (Figure 2) was E. coli (34.1\%) (Figure 3). followed by Klebsiella pneumoniae (15.1\%), Enterococcus species (11.4\%), Coagulase Negative Staphylococcus (CoNS) (1.6\%), Staphylococcus aureus (7.02\%), Acinetobacter species (3.2\%), Citrobacter species (0.5\%), Pseudomonas aeruginosa (5.9\%), and Proteus species (1.6\%) (Table 2).

Nearly all the isolates (Gram negative and Gram positive) were found to be resistant against most of the commonly used oral antibiotics.

Overall Gram negative pathogens showed more resistance as compared to Gram positive organisms for empirical antibiotics commonly 
used to treat UTI. In the present study, antibiotic sensitivity pattern (Table 3) of Gram-negative isolates are Imipenem (94.64\%), Tobramycin (87.5\%), PipercillinTazobactum (75\%), Amikacin (74.7\%), Gentamicin (63.39\%), Amoxicillin-Clavulinic acid(61.6\%), Ceftazidime-Clavulanic acid (58.03\%), Ceftriaxone (25.8\%), Norfloxacin $(25.4 \%)$.

In this study, Gram-positive organisms showed the following sensitivity pattern: Linezolid (100\%), Vancomycin (67.7\%), Amikacin (54.05\%), Amoxycillin-Clavulanic acid (52\%), Ceftriaxone (51.42\%), Norfloxacin (16\%), TrimethoprimSulfamethoxazole (46\%), and Gentamycin (43\%).

The susceptibility of diabetic patients to UTI could be explained by diminished neutrophil response, lower urinary cytokines, and leukocyte concentrations, which might facilitate the adhesion of microorganisms to uroepithelial cells.

Total 185 patients 75 were males \& 110 were females with mean age of 65years. Commonest age group in the present study was 46-55 years followed by 56-65 years and 36-45 years. Similar age and Sex distribution was observed in majority of the studies. In a study done by Jennifer et al., (2009) ${ }^{10}$ shows that UTI is more common in above 45 years age group and in study by Mishra et al., $(2015)^{9}$ above 60 years is more common. In post menopausal women this may be due to non-secretory status, less acidic $\mathrm{pH}$ of vaginal surface and poor hygienic conditions leads more chance of getting infection and in 36 to 45 years sexually active women poor hygienic condition causes the infection. ${ }^{97}$.

In the present study, the prevalence of UTI in female $(59.5 \%)$ was high as compared to male (40\%). A Study by Mishra et al., ${ }^{9}$ and Jennifer et al., ${ }^{10}$ showed similar prevalence rate of UTI in females as compared to males. The explanation for gender difference is anatomic reason; the short and straight urethra and short distance between the ostium of the urethra and the anus contribute to easy colonization of the peri-urethral region with enteric bacteria.

Burning micturition and dysuria were the most common presenting symptoms in the present study. Whereas only dysuria is the predominant symptom in Mishra et al., ${ }^{9}$ and Jennifer et al., ${ }^{10}$ study groups.

Presence of pyuria in female patients were more predominant $(37 \%)$ when compared to males (30\%). Study by Hamdan et al., (2015) in Sudan shows that there is no association between pyuria and prevalence of UTI. ${ }^{14}$

Table.1 Age distribution of diabetic UTI cases

\begin{tabular}{|l|c|c|}
\hline AGE GROUP & Number of Patients & Percentage \\
\hline $\mathbf{2 5 - 3 5}$ & 12 & 6.5 \\
\hline $\mathbf{3 6 - 4 5}$ & 44 & 23.8 \\
\hline $\mathbf{4 6 - 5 5}$ & 51 & 27.6 \\
\hline $\mathbf{5 6 - 6 5}$ & 48 & 25.9 \\
\hline $\mathbf{6 6 - 7 5}$ & 27 & 14.6 \\
\hline $\mathbf{7 6 - 8 5}$ & 3 & 1.6 \\
\hline Total & $\mathbf{1 8 5}$ & $\mathbf{1 0 0 . 0}$ \\
\hline
\end{tabular}


Table.2 Isolated uropathogens

\begin{tabular}{|l|c|c|}
\hline \multicolumn{1}{|c|}{ Uropathogens } & Number of Patients & Percent \\
\hline E.coli & 63 & 34.1 \\
\hline No growth & 36 & 19.5 \\
\hline Klebsiella & 28 & 15.1 \\
\hline Enterococci & 21 & 11.4 \\
\hline Staph.aureus & 13 & 7.02 \\
\hline Pseudomonas & 11 & 5.9 \\
\hline Acinetobacter & 6 & 3.2 \\
\hline Coagulase negative Staphylococci & 3 & 1.6 \\
\hline Citrobacter & 1 & 0.5 \\
\hline Total & 185 & 100.0 \\
\hline
\end{tabular}

Table.3 Antibiotic Sensitivity Pattern for Gram Negative Isolates

\begin{tabular}{|l|c|c|}
\hline Drug & Sensitive (\%) & Resistance (\%) \\
\hline Imp & $106(94.64)$ & $6(5.35)$ \\
\hline Tob & $7(87.5)$ & $1(12.5)$ \\
\hline C & $4(80)$ & $1(20)$ \\
\hline Ak & $83(74.77)$ & $28(25.22)$ \\
\hline Gen & $71(63.39)$ & $41(36)$ \\
\hline Amc & $69(61.6)$ & $43(38)$ \\
\hline Cac & $65(58)$ & $47(41)$ \\
\hline Caz & $61(54)$ & $51(45)$ \\
\hline Cpd/cv & $51(45)$ & $61(54)$ \\
\hline Amp & $47(41)$ & $65(58)$ \\
\hline Cot & $15(39)$ & $23(60)$ \\
\hline Ctr & $29(25)$ & $83(74)$ \\
\hline Nx & $28(25)$ & $82(74)$ \\
\hline Azm & $2(1.7)$ & $110(98)$ \\
\hline Cpd & 0 & $51(100)$ \\
\hline
\end{tabular}

Table.4 Comparison of common organisms isolated from different study

\begin{tabular}{|c|c|c|}
\hline Study & Year & Proportion of predominant organisms in various Studies \\
\hline Present study & 2016 & $\begin{array}{l}\text { E.coli }(34.1 \%)>>\text { Klebsiella pneumoniae }(15.1 \%) \\
>>\text { Enterococci }(11.4 \%)>>\text { staph.aureus }(\mathbf{7 . 0 2 \%})\end{array}$ \\
\hline Mishra et al., ${ }^{9}$ & 2015 & E.coli $(35.8 \%)>>$ Klebsiella pneumoniae $(18.9 \%)>>$ Enterococci $\operatorname{spp}(12.9 \%)$ \\
\hline Khan et al.," & 2015 & $\begin{array}{l}\text { E.coli }(52.4 \%)>>\text { Klebsiella } \\
\text { pneumoniae }(12.3 \%)>>\text { Citrobacter }(9 \%>>) \text { Enterococci } \\
\operatorname{spp}(12.9 \%)>>\text { Proteus }(5.3 \%)\end{array}$ \\
\hline $\begin{array}{l}\text { Choudary et } \\
\text { al., } 15\end{array}$ & 2014 & $\begin{array}{l}\text { E.coli }(55 \%)>>\text { Klebsiella pneumoniae }(17.5 \%)>>\text { Staph aureus }(12.5 \%)>> \\
\text { Enterococci } \mathrm{spp}(10 \%)>>\text { Pseudomonas } \mathrm{spp} .(5 \%)\end{array}$ \\
\hline $\begin{array}{l}\text { Jennifer et al., } \\
10\end{array}$ & 2009 & $\begin{array}{l}\text { E.coli }(71 \%)>>\text { Klebsiella pneumoniae }(13.5 \%)>>\text { Pseudomonas } \\
\text { spp. }(9 \%) \text { Citrobacter }(2 \%) \text {, Among GPC Enterococci } \operatorname{spp}(59 \%)\end{array}$ \\
\hline $\begin{array}{l}\text { Akram et al., } \\
16\end{array}$ & 2007 & $\begin{array}{l}\text { E.coli }(61 \%)>>\text { Klebsiella pneumoniae }(22 \%)>>\text { Staph } \\
\text { aureus }(7 \%)>>\text { Pseudomonas spp. }(4 \%)>>\text { Acinetobacter } \text { spp. }(3 \%)\end{array}$ \\
\hline
\end{tabular}


Fig.1

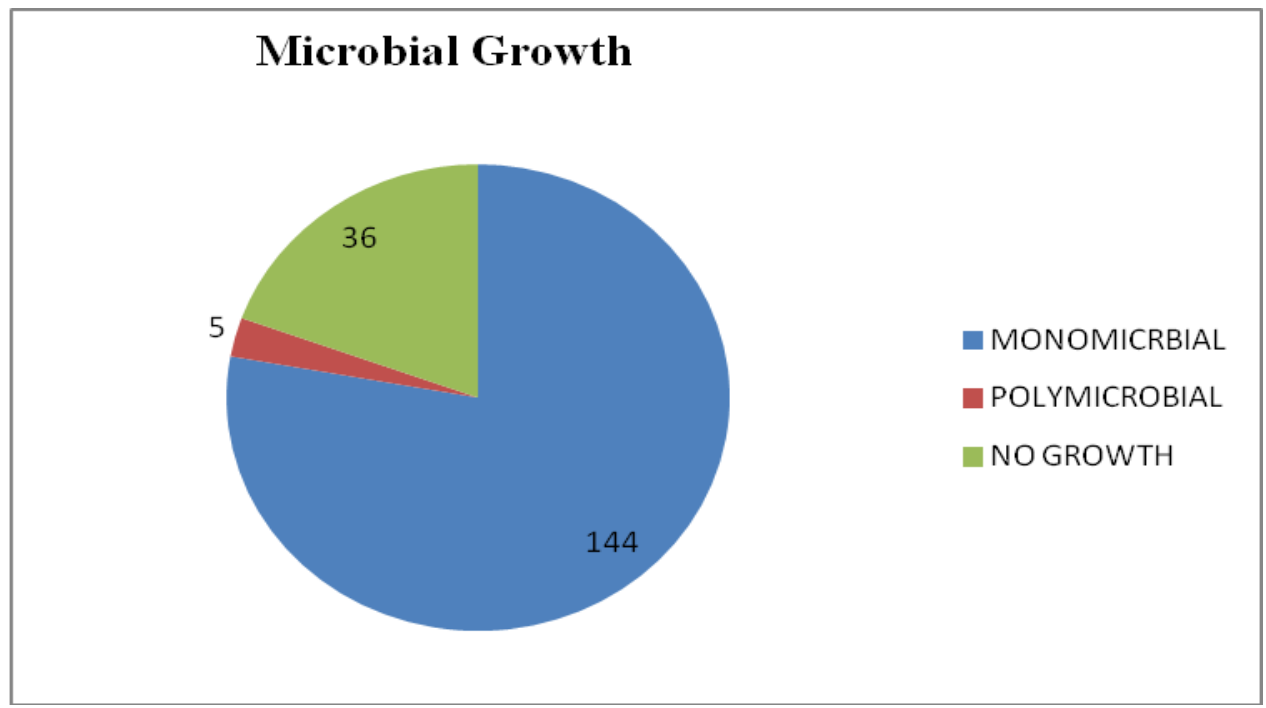

Fig.2 Distribution of uropathogens

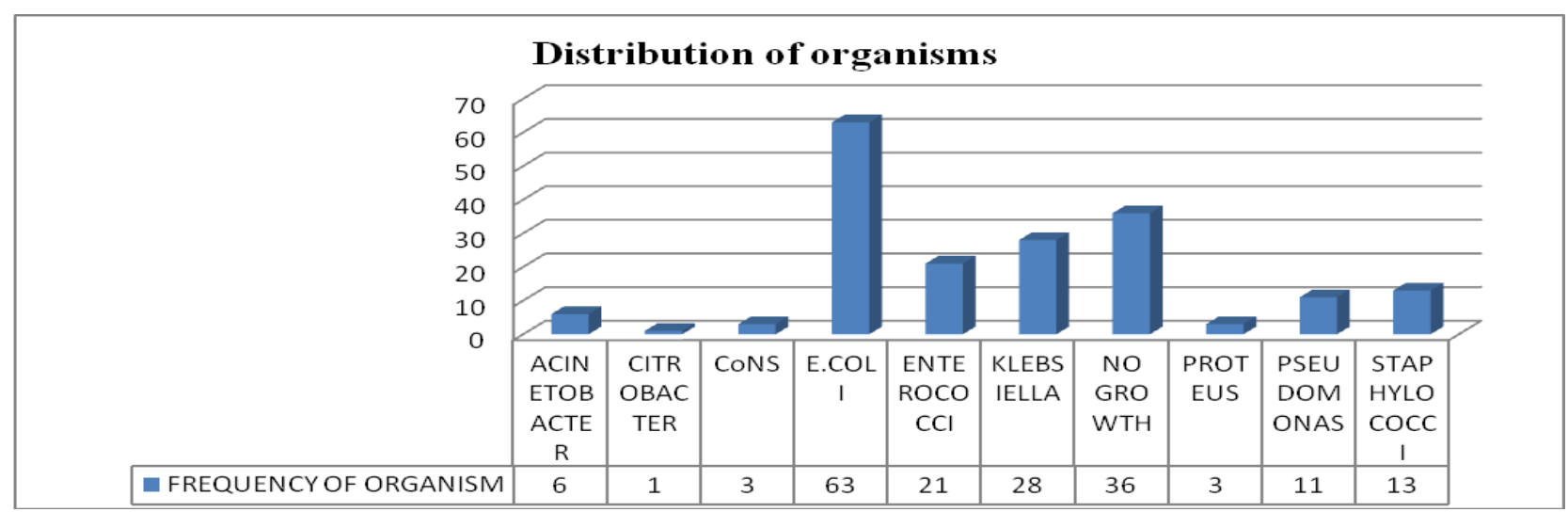

Fig.3 Growth of E. coli on MacConkey agar

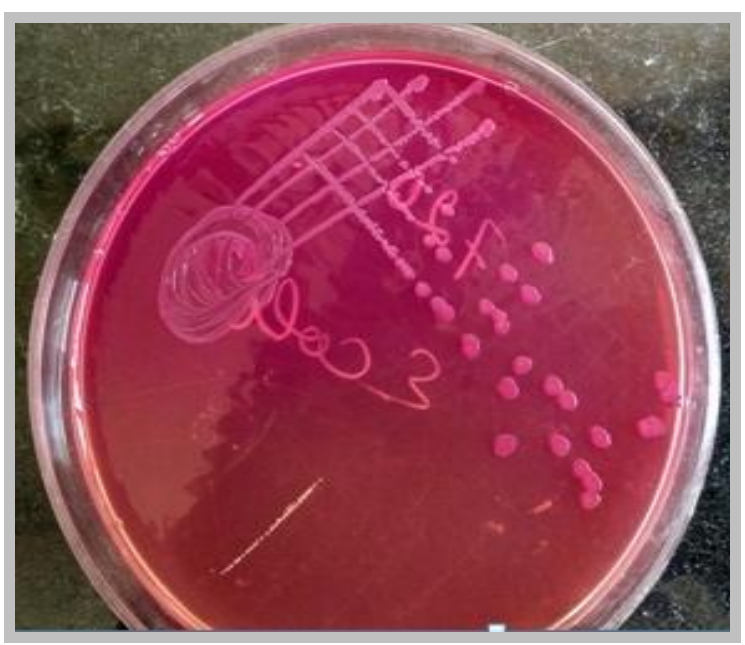


Studies by Mishra et al., ${ }^{9}$, Akram et al., ${ }^{16}$ and Jennifer et al., ${ }^{10}$ revealed the involvement of Gram negative enteric organisms that commonly causes urinary tract infections, such as E. coli, the Klebsiella species, and the Proteus species similarly, the predominant number of pathogens isolated in our study were also Gram negative bacilli (Table 4).

In our study proportion of Gram negative isolates was $60.54 \%$ almost similar to other studies like Khan et al., ${ }^{11}(52.4 \%)$ and Jennifer et al., ${ }^{10}$ (71\%).

Proportion of Gram positive isolates in our study was $20 \%$, similar to other studies by Khan et al., ${ }^{11}(32 \%)$ and whereas in a study by Prakash D et al., ${ }^{17}$ only (9.68\%). The probable reason may be regional variation in prevalence of these organisms.

Among Gram negative uropathogens, Escherichia coli was the most common isolated organism (34.1\%) followed by Klebsiella pneumoniae (15.1\%), Pseudomonas spp. (5.9\%), Proteus (1.6\%). Earlier studies by Mishra et al., ${ }^{9}$, Khan et al., ${ }^{11}$, Choudhary et al., ${ }^{15}$ and Jennifer et al., 10 shows E.coli was the most predominant isolated organism, followed by Klebsiella spp., These results suggestive of several factors are responsible for attachment of Enterobacteriaceae to the uroepithelium like, they colonize the urogenital mucosa with adhesin and pili. ${ }^{12,13,14}$

Among Gram positive isolates, Enterococcus Species were the most commonly isolated organism $21 \quad(11.4 \%)$ followed by Staphylococcus aureus 13 (7.02\%), in contrast with other study where Enterococcus species were found as the most frequent organism $(15 \%)$, followed by Coagulase negative Staphylococcus (1.6\%). Study by Mishra et al., shows Enterococcus spp. followed by Coagulase negative Staphylococcus, by Akram et al., ${ }^{16}$,
Staphylococcus aureus is the predominant among Gram positive organisms.

In the present study, E.coli were highly sensitive to Imepenem(93\%), followed by Amikacin (84\%), Gentamicin (74\%), Amoxyclav (65\%). They were highly resistant to Azithromycin (96\%), followed by Ceftriaxone (74\%), Norfloxacin (71\%).

Klebsiella pneumoniae isolates were sensitive to Imipenem (96\%) followed by Ceftazidime with clavulinic acid(75\%), Amoxy-clav (71\%). They were $100 \%$ resistant to Azithromycin followed by Norfloxacin(78\%).

Pseudomonas aeruginosa were more sensitive to Imipenem (90\%), Tobramycin (85\%), Piperacillin with Tazobactum(66\%). They were $100 \%$ resistant to Azithromycin, followed by Norfloxacin (72\%), Ampicillin (90\%). Resistance to Fluoroquinolones (Norfloxacin) (74\%) were high among Gram negative isolates in this study is similar to other studies by Khan et al., ${ }^{11}$ (79\%) and by Prakash D et al., ${ }^{17}(90 \%)$. This reduced susceptibility is due to irrational use of antibiotics.

Hence among Gram negative isolates, most effective antibiotic was Imipenem followed by Amikacin and Gentamicin and among Gram positive isolates (S. Aureus) most effective antibiotic was Linezolid, Clindamycin, Vancomycin followed by Amikacin.

This difference in percentage of resistance may be because of the number of each isolate in different studies are different and the sample size in each studies were also different.

Another reason may be the geographical variation in the distribution of resistant organisms. 
To conclude E.coli was the commonest isolate followed by Klebsiella pneumoniae, Enterococci spp, Pseudomonas aeruginosa, Staphylococcus aureus and Acinetobacter spp. Most effective antibiotic for Gram negative isolates was Imipenem followed by Amikacin and Gentamicin. These isolates showed highly resistance to flouroquinolones. S. aureus isolates were highly sensitive to Linezolid, followed by Vancomycin, Amikacin. This study would help to make antibiotic policy in our hospital which may helps in better selection of antibiotic therapy to prevent misuse or overuse of antibiotics. Before starting antibiotic therapy to the patients, culture \& sensitivity should be done to know the causative organism and its sensitivity pattern in uncomplicated urinary tract infection to avoid the development of multi drug resistance. Before prescribing the antimicrobial therapy, a thorough knowledge of the susceptibility patterns of the uropathogens is essential to avoid incongruous and irrational antibacterial usage and to restrain the further development of drug resistance.

\section{Acknowledgement}

We thank Dr. Gayathree L, Assistant Professor, Department of Microbiology HIMS, Hassan and Dr. Ravikumar B. C, Prinicipal / Director, Hassan Institute of Medical Sciences, Hassan, India.

\section{References}

1. Noor N, Ajaz M., Rasool SA., Pirzada ZA. Urinary tract infections associated with multidrug resistant enteric bacilli, characterization and genetical studies. Pak J Pharm Sci. 2004; 17: 115-1233.

2. Wilson ML, Gaido L. Laboratory diagnosis of urinary tract infections in adult patients. Clin Infect Dis. 2004; 38:1150-1158.
3. Sridhar CB, Anjana S, Mathew JT. Acute Infections. In: Ahuja MMS, Tripathy BB, Sam Moses GP, Chandalia HB, Das AK, Rao PV, editors. RSSDI Text Book of Diabetes Mellitus. Hyderabad, India: 2002. pp. 471-8. Chap-34.

4. Bending J. Schrier R, editor. The Kidney and Renal Tract. Diabetes: Clinical Management 8thedition, edited by. 1990:286-7. Chap-25.

5. Newell A, Riley P, Rogers M. Resistance patterns of urinary tract infections diagnosed in a genitourinary medicine clinic. Int J STD AIDS 2000; 11: 499500.

6. Orrett FA, Shurland SM. The changing patterns of antimicrobial susceptibility of urinary pathogens in Trinidad. Singapore Med J. 1998 Jun; 39(6):2569.

7. Mandal J, Srinivas A N, Buddhapriya D, Parija S C, Antibiotic resistance pattern among common bacterial uropathogens with a special reference to ciprofloxacin resistant Escherichia coli. Indian J Med Res 136, November 2012, pp 842-849.

8. Cheesbrough, M., 2001. District laboratory practice in tropical countries, Part 2.Cambridge University Press, Cambridge, United Kingdom.105-115p.

9. Mishra R et al: Bacteriological profile and sensitivity pattern of microorganisms causing Urinary Tract Infection at a tertiary care center in eastern Uttar Pradesh. International Journal of Biomedical and Advance Research 2016; 7(6): 292-297.

10. J. Janifer, S. Geethalakshmi, K. Satyavani, and V. Viswanathan. Prevalence of lower urinary tract infection in South Indian type 2 diabetic subjects. Indian $\mathrm{J}$ Nephrol. 2009 Jul; 19(3): 107-111.

11. Khan R, Saif Q, Fatima K, Meher R, Shahzad HF, Anwar KS. Clinical and Bacteriological Profile of UTI Patients 
Attending a North Indian Tertiary Care Center. Journal of Integrate Nephrology and Andrology 2015: 2(1).

12. Ahmed SM, Jakribettu RP, koyakutty S, Arya B, Shakir VPA. Urinary tract infections - an overview on the prevalence and the anti-biogram of gram negative uropathogens in a tertiary care centre in north Kerala, India. Journal of Clinical and Diagnostic Research, 2012:S:6(7): 1192-1195

13. Haider G, Zehra N, Munir AA, Haider A. Risk factors of urinary tract infection in pregnancy. J Pak Med Assoc.2010:60(3).

14.Hamdan Z, Kubbara E, Adam AM, Hassan OS, Suliman SO, Adam I.Urinary tract infections and antimicrobial sensitivity among diabetic patients at Khartoum,
Sudan. Annals of Clinical Microbiology and Antimicrobials.2015:14:26.

15. Chaudhary Bl, Chandra C, Shukla S. Bacteriology of urinary tract infection and antibiotic susceptibility pattern among diabetic patients. Int. J. Bioassays, 2014, 3 (08), 3224-3227.

16. Akram M, Shahid M, Khan SU .Etiology and antibiotic resistance patterns of community-acquired urinary tract infections in J N M C Hospital Aligarh, India. Annals of Clinical Microbiology and Antimicrobials.2007:6:4.

17. Prakash D and Saxena RS. Distribution and Antimicrobial Susceptibility Pattern of Bacterial Pathogens Causing Urinary Tract Infection in Urban Community of Meerut City, India. ISRN Microbiology. 2013:13:1-13.

\section{How to cite this article:}

Rashmi, B.K. and Venkatesha, D.T. 2017. Antibiogram of Urinary Pathogens in Patients with Diabetes Mellitus - Experience from a Tertiary Care Hospital. Int.J.Curr.Microbiol.App.Sci. 6(10): 4830-4837. doi: https://doi.org/10.20546/ijcmas.2017.610.451 